\title{
Changing Socio-Economic Profile of Thiruvananthapuram District, Kerala
}

\author{
Charutha Reghunathan, Dr. R. Anilkumar \\ Dept. of Geography, University College, Thiruvananthapuram, Kerala, India
}

\begin{abstract}
Population is the soul of a region. Its characteristics are the base for the existence and development of the region. The population studies is a broad social science discipline concerned with the study of human populations in relation to their size, composition, the changes occurring over time and the factors associated with these changes. The quality of the life of a community depends on the characteristics of population which includes its size and distribution by age, sex, occupation, marital status and the geographical area of its existence. A comparable picture of the above characteristics over a period of time can also explain the development process of a locality. An accurate assessment demands an understanding of the changing attributes which can be better understood only by knowing the present scenario. The work mirrors the evolved and existing condition of the population of Thiruvananthapuram district on the basis of important socio- economic attributes and its spatial variation for the last thirty years and aims to provide a better understanding of the prevailing situation of the district.
\end{abstract}

\section{Introduction}

Population is a group of living individuals set in a frame that is limited and defined in respect to both time and space. It is an interacting or potentially interactive group of individuals usually of the same species. There are certain attributes of population which distinguish them from individual organisms like they have a structural organization, a functional unity and a pattern of growth and development that is unlike individuals, they have group attributes and statistical properties (Prabhakar, V.K., 2001). The study of these group attributes provides an insight into the characteristics of population in an area. Major factors considered while studying population of an area includes its size or numbers, its structure and characteristics, its distribution and the changes taking place in it over a period of time. The study of population is not limited to the study of variables but also their relationship and thus includes both qualitative and quantitative aspects of human population. There are four ways in which the number of people in any area can undergo change: (1) children may be born in that area (2) the inhabitants of that area may die (3) people from other area may move into that area and (4) inhabitants of that area may move out (Asha A Bhende and Tara Kanitkar, 2010).

Among the Indian states, Kerala is unique as it is demographically ahead of the rest of the country and is in the final stages of demographic transition (to low fertility and mortality) (Rajan and Zacariah, 2009). The state has an outstanding track record in low birth and death rates and high life expectancy. It is also famed for having a female population that has outnumbered and outlined the male population. Kerala is home to $2.76 \%$ of India's people, and density at 859 persons per $\mathrm{km}^{2}$ (2011 census). Thiruvananthapuram, the state capital and the southern most district, has an outstanding position with its essential natural resources base, is a centre of many governmental and non governmental institutions, is the site of one of Asia's largest IT hubs and has many proposed and up coming new projects in store. This demands a better knowledge of the demographic variables as it is the major factor involved in these changes. Understanding of the demographic datasets will be helpful in designing human development projects, provides a realistic picture of the district and helps to identify the thrust areas. With this intention the study aims to analyse the scenario of population change in the district for a time period from 1981 to 2011 and major factors considered includes variations in population size, density, age structure, sex ratio, literacy, and occupation structure.

\section{Study Area}

Thiruvananthapuram, the capital of Kerala came into existence with the linguistic re-organization of states on $1^{\text {st }}$ November 1956. The district lies between $8^{\circ} 17^{\prime} 25^{\prime \prime}$ to $8^{\circ} 51^{\prime} 46^{\prime \prime}$ North latitudes and $76^{\circ} 40^{\prime} 25^{\prime \prime}$ to $77^{\circ} 17^{\prime}$ '" East longitudes (Fig.1). It covers an area of $2192 \mathrm{~km}^{2}$ which accounts for $5.64 \%$ of the total area of the state The district stretches along the shores of Arabian Sea for a distance of 78kms. Kollam district is on the North and Thirunelveli and Kanyakumari Districts of Tamil Nadu are on the East and the South respectively. The district can be divided into three geographical regions - highlands, midlands and lowlands. The district includes six taluks namely Chirayinkeezhu, Nedumangadu, Thiruvananthapuram, Neyyattinkara, Varkala and Kattakada, 115 Villages, one corporation and four municipalities. There are 12 Community Development 
Blocks and 73 Panchayats in the district. The district is the most densely populated among the districts of Kerala and its total population is 3,301,427 (2011 census) in which 46.33 percent people resides in rural area 53.66 in urban area. The district being the capital is the centre of many projects and these changes which evolved within a couple of decades have definitely affected the population structure of the district and indirectly the life of the residents and their standard of living.

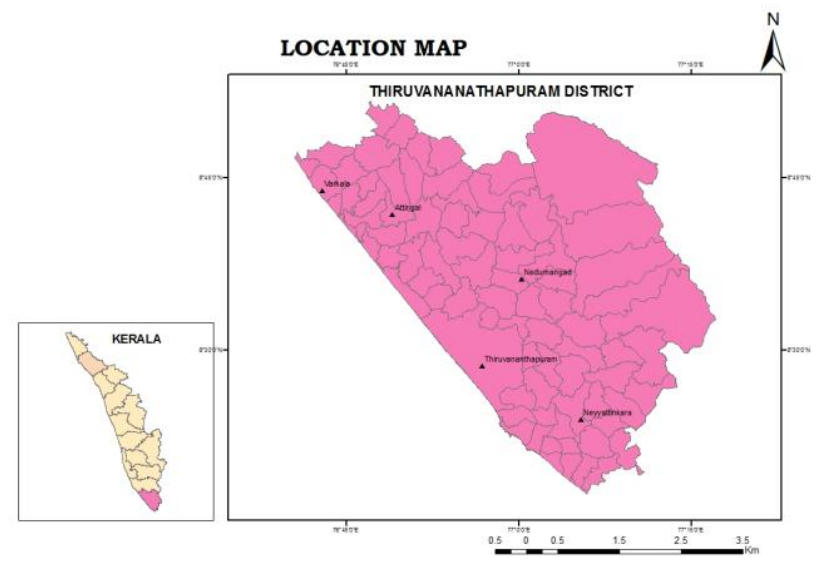

Fig. 1

The work makes use of census data published by the Census of India. Arc GIS 9.3 software is used for mapping purpose. Further processing of the data is done using statistical techniques.

\subsection{Population Size}

\section{Analysis}

The total population of the district based on 2011 census is 3,301,427 persons, in which 1,581,678 are males and 1,719,749 are females. During the 1981 census, the total population was 2,596,112 and in that $1,279,150$ were males and 1,316,962 females. It increased to 2,946,650 with 1,447,594 male and 1,499,056 females in the 1991 census. 2001 census saw an increase in total population to 3,234,356. Male and female population were 1,569,917 and 1,664,439 respectively. Thus within the last three decades there is an increase of 705,315 persons in the district (Fig.2).

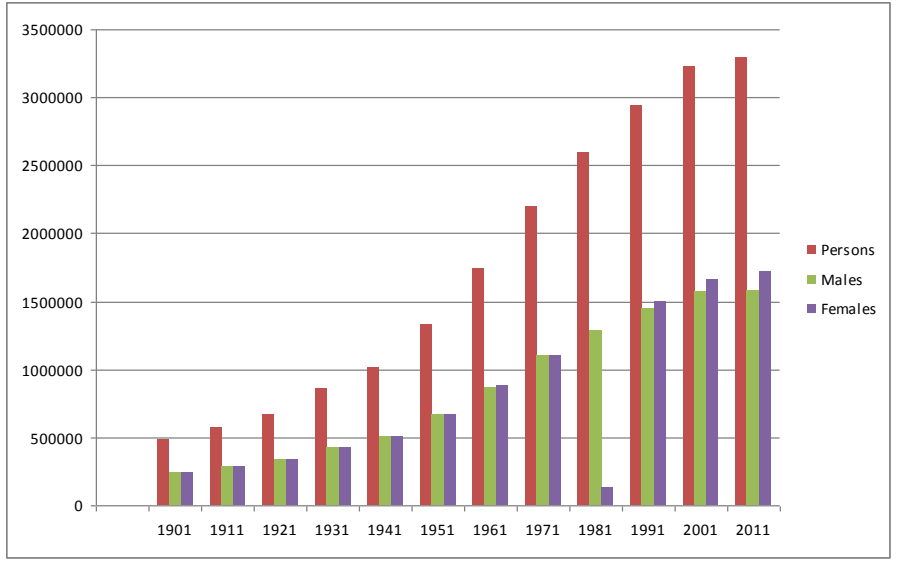

Source: The District Census Handbook, Census of India

Fig. 2

Considering the panchayats, Parassala panchayat topped in population size with 40,867 persons followed by Ulloor panchayat with 38,277 persons in the 1981 census were as in the recent one Karakulam panchayat topped with a population of 52,417. Male population is 25,397 and female 27,020. Among the municipalities, Neyyatinkara has highest population with 70,850 persons. Thiruvananthapuram Corporation shows a steady increase from 483,086 in 1981 to 966,856 in 2011(Fig.3). 


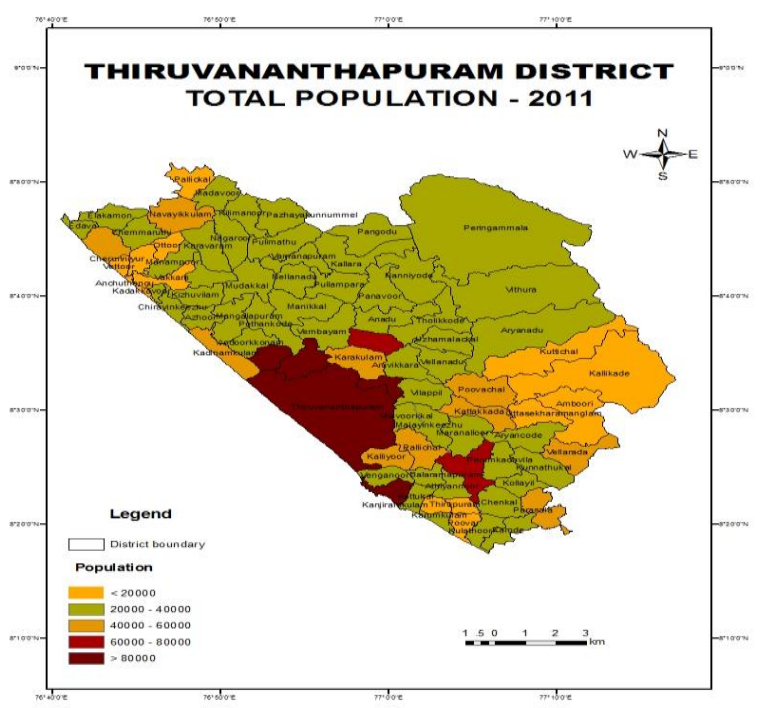

Fig. 3

\subsection{Growth rate}

Population growth rate is the increase or decrease in a region's population during a period of time and is expressed as a percentage of the population at the start of that period. It reflects the number of births and deaths during the period and the number of people migrating to and from an area. Growth rate acts as a key unifying variable in the various facets of population studies. The importance of population growth rate lies partly in its central role in forecasting future population trends; indeed if the form of density dependence were constant and known, then the future population dynamics could to some degree be predicted. (http://www.ncbi.nlm.nih.gov/pmc/articles/PMC1693026/). In the case of Thiruvananthapuram district, a steady decline in the growth rate is visible, which can be taken as a positive development indicator. It was 17.54 percent at the beginning of the century, increased in the 1981 census to 18.08 percent, 13.5 percent during 1991 , 9.76 percent during 2001 and now it reached to about 2.07 percent. If the rural and urban growth rates are considered, the rural growth rate is showing a negative trend with -28.8 percent changes which was 9.97 percent in the previous census. Urban population shows a tremendous increase with 62.22 percent growth rate to the previous 9.36 percent (Fig.4).

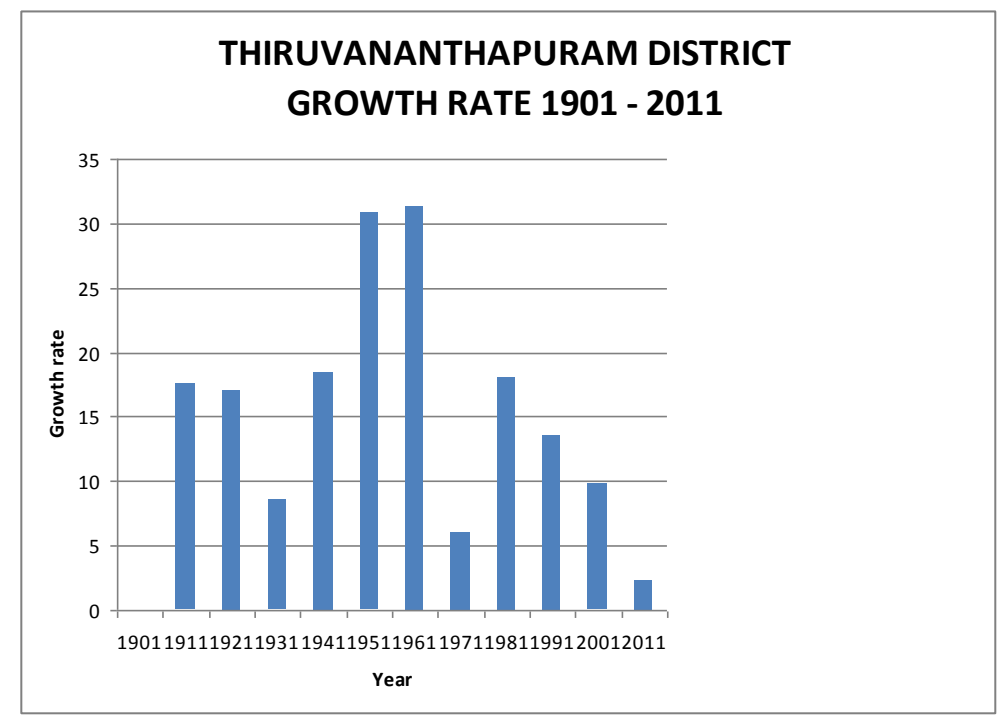

\subsection{Population Density}

Fig. 4

The population density which shows the number of persons per unit of area is an important measure in population studies. Density of population impacts the environment and ultimately the quality of life of people thus it is a very useful tool for the analysis of mans distribution in space. Thiruvananthapuram district ranks first in density in the state with 1509 persons / sq.km (2011 census). In the previous census it had a second position 
with 1476 persons /sq.km . During the year 1981, the density was 1184, it increased to 1344 in the 1991(Fig.5). Thiruvananthapuram Corporation (6448) is the thickly populated region of the district.

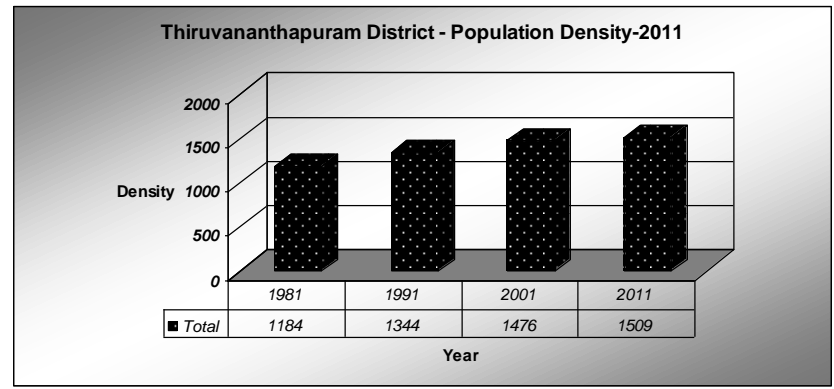

Fig. 5

Among the panchayats, in the 1981 census, Anchuthengu panchayat (4653) has the highest population density followed by Chettivilakam panchayat (3437) (Fig.6). Anchuthengu panchayat still tops in the population density in recent census with 5177 persons/ sq.km followed by Venganoor panchayat (3554). Among the municipalities, Varkala (2693) has the highest population density(Fig.7)

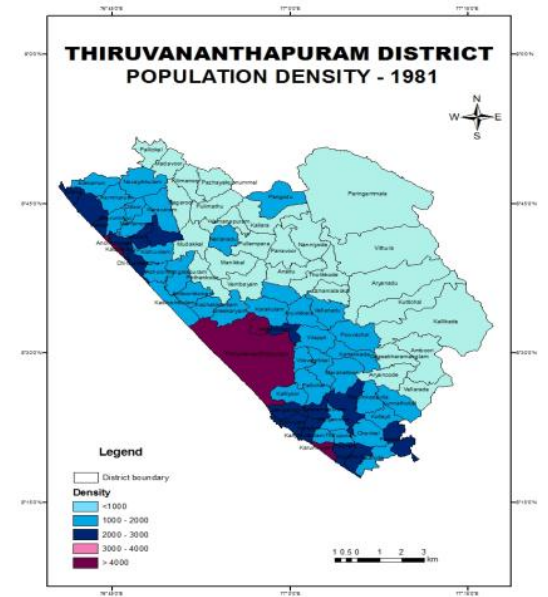

Fig. 6

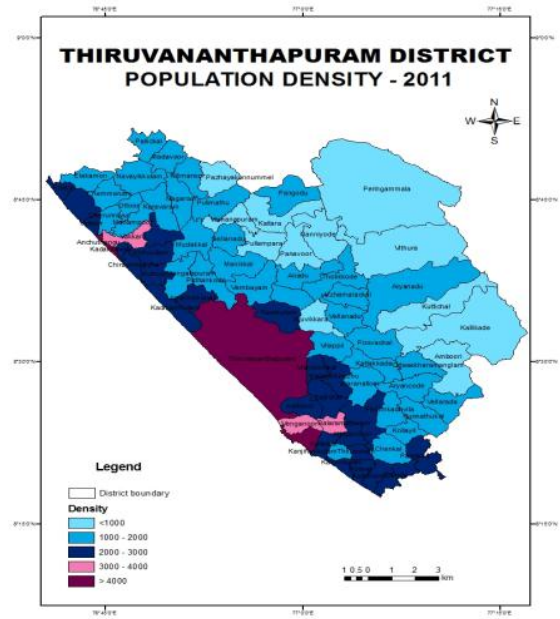

Fig. 7

\subsection{Age and Sex Structure}

A society's age and sex distribution has important implications for socioeconomic and demographic development (Keyfitz, 1965). Of all the characteristics of human population, age and sex are arguably the most important and relevant for demographers. So important are they for demographic analysis that they are referred to as "the demographic variables" (Bouge,1969). Their importance lies in the fact that the interaction of the demographic processes produces a population's age and sex structure (Horiuchi and Preston, 1988) and the demographic processes are themselves affected by the age and sex structure. Changes in the age distribution of a 
population have consequences in the educational, political and economic life of region.(Keyfitz and Flieger, 1971).

\subsubsection{Age Structure}

The United Nation has defined age as "the estimated or calculated interval of time between the date of birth and the date of census, expressed in completed solar years." Age structure is the direct output of birth rate, death rate and migration of a region. So changes in this not only influence the demographic aspects but also social, economic and political structure of a region. Age structure of the district for the year 1981 reveals that, population of age 0-9 is highest in the district. About 531,485 people are within this age limit (Table 1). Same is the case in 2001 census which has 515,621 people belonging to this age limit (Table 2). Increase in the youth population shows that the demand for better planning in all the sectors including infrastructure and occupation as in inevitable as the earning group needs better employment and living facilities in the district.

Table 1

\begin{tabular}{lrrr}
\multicolumn{1}{c}{$\begin{array}{c}\text { Age- } \\
\text { group }\end{array}$} & \multicolumn{3}{c}{1981} \\
\cline { 2 - 4 } & Persons & Males & Females \\
All ages & 2596112 & 1279150 & 1316962 \\
$0-9$ & 531485 & 268863 & 262622 \\
$10-14$ & 304058 & 152941 & 151117 \\
$15-19$ & 310870 & 149591 & 161279 \\
$20-24$ & 290376 & 137344 & 153032 \\
$25-29$ & 242928 & 118098 & 124830 \\
$30-34$ & 181533 & 92365 & 89168 \\
$35-39$ & 155689 & 78140 & 77549 \\
$40-44$ & 117896 & 59082 & 58814 \\
$45-49$ & 117856 & 58518 & 59338 \\
$50-54$ & 85939 & 42711 & 43228 \\
$55-59$ & 73035 & 35969 & 37066 \\
$60-64$ & 68885 & 33712 & 35173 \\
$65-69$ & 49597 & 23429 & 26168 \\
$70+$ & 65387 & 28226 & 37161
\end{tabular}

Table 2

\begin{tabular}{lrrr}
\multicolumn{1}{c}{ Age-group } & \multicolumn{3}{c}{2001} \\
\cline { 2 - 4 } & \multicolumn{1}{c}{ Persons } & Males & Females \\
\hline \multicolumn{1}{c}{1} & \multicolumn{1}{c}{3} & \multicolumn{1}{c}{4} \\
\hline All ages & 3234356 & 1569917 & 1664439 \\
$0-9$ & 515621 & 262544 & 253077 \\
$10-14$ & 284217 & 145039 & 139178 \\
$15-19$ & 276480 & 137914 & 138566 \\
$20-24$ & 290699 & 136891 & 153808 \\
$25-29$ & 285707 & 132931 & 152776 \\
$30-34$ & 265249 & 125504 & 139745 \\
$35-39$ & 266375 & 126298 & 140077 \\
$40-44$ & 215382 & 105682 & 109700 \\
$45-49$ & 214266 & 106580 & 107686 \\
$50-54$ & 154025 & 77204 & 76821 \\
$55-59$ & 125420 & 61164 & 64256 \\
$60-64$ & 109846 & 51111 & 58735 \\
$65-69$ & 92114 & 40948 & 51166 \\
$70+$ & 135224 & 58099 & 77125 \\
Age not stated & 3731 & 2008 & 1723
\end{tabular}

\subsubsection{Sex ratio}

"The equality between women and men is a matter of human rights and a condition for social justice and is also a necessary and fundamental prerequisite for equality, development and peace"(UN Forth Conference on Women).The sex ratio is the most popular index of sex composition in demographic and other scholarly analyses. The human population exhibits certain inherent characteristic in terms of sex composition (Joshi and Tiwari, 2011). There are different tools to measure gender equity in population and sex ratio is one such tool. The ratio between male and female is called sex ratio. In Indian context, sex ratio is defined as number of females per 1000 males. It is an important social indicator which measures the extent of prevailing equality between males and females and it is an outcome of interplay of sex differentials in mortality, sex selective migration, sex ratio at birth and times sex differential in population enumeration (Census of India, 2001). This variable exerts its influence in all aspects of population including occupation structure, marriage, and migration and on the whole population growth and causes economic and social changes in the area. 


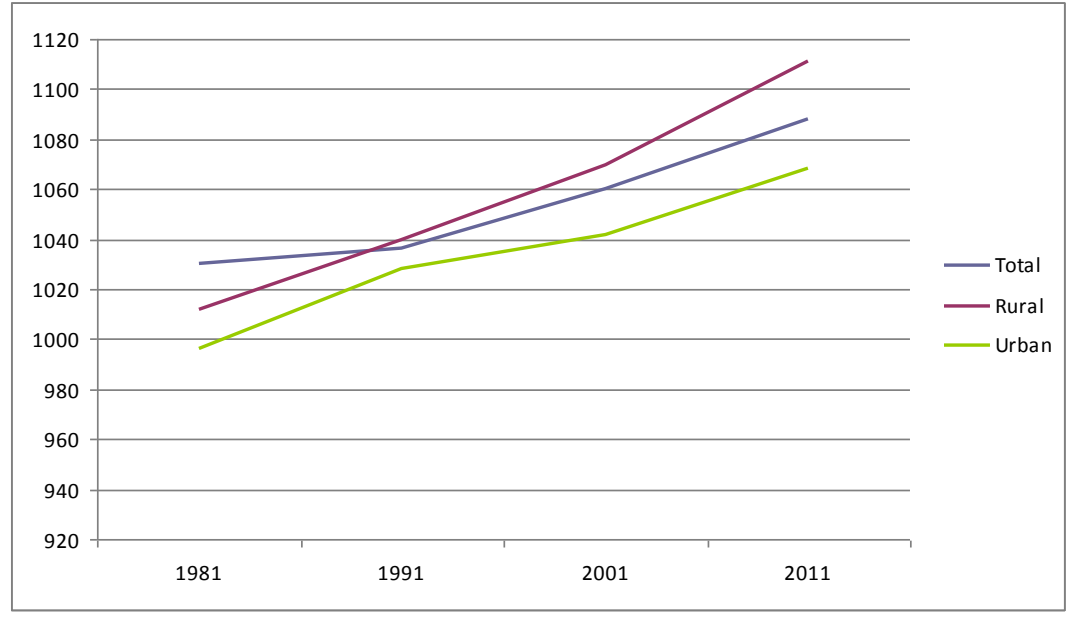

Fig. 8

The district shows a favourable increasing sex ratio. It increased from 1030 in 1981 to 1088 in the latest census. Rural and urban areas also follow the same trend with 1012 to 1111 in 2011 census in case of rural areas and 996 to 1068 in the case of urban areas (Fig.8). Based on the 2011 census, Vakkom panchayat (1345) shows the highest sex ratio followed by Edava panchayat (1263). Thiruvananthapuram Corporation has a sex ratio of 1052. Except for Andoorkonam panchayat (978.59), all other panchayats have favourable sex ratio.

\subsection{Literacy}

Development of a society is reflected in the level of literacy and attainment of education.They also affects demographic characteristics of a society like fertility, mortality and migration. Their contribution in improving quality of life of society is also of great importance and the trends in literacy are considered as an index of the pace at which the socio-economic transformation of a society is taking place (Mitra, K.C., 2012). Literacy according to UN is "the ability of a person to read and write with simple understanding, a short simple statement on his everyday life" (UN, 1970). Literacy is considered as a major determinant of development. Adult literacy is one of the components used in the Human Development Index as well as the Physical Quality of Life Index. According to Jain and Visaria (1988), studies have shown that literacy, particularly female literacy is a major determinant of infant mortality. High infant mortality rate is seen in the case of illiterate mothers when compared to that seen among the literate mothers (Nair et al, 1995).

Based on the 2011 census, the literacy rate of the district is 92.66 per cent. Rural literacy rate is 91.98 per cent and urban literacy rate is 93.24 per cent. In the year 1981, the total literacy rate was 70.5 per cent and 68.84 per cent and 75.42 per cent for rural and urban areas respectively (Fig.9). The male literacy rate increased from 75.29 per cent for males in 1981 to 94.60 per cent in 2011 and female from 65.85 per cent to 90.89 per cent.

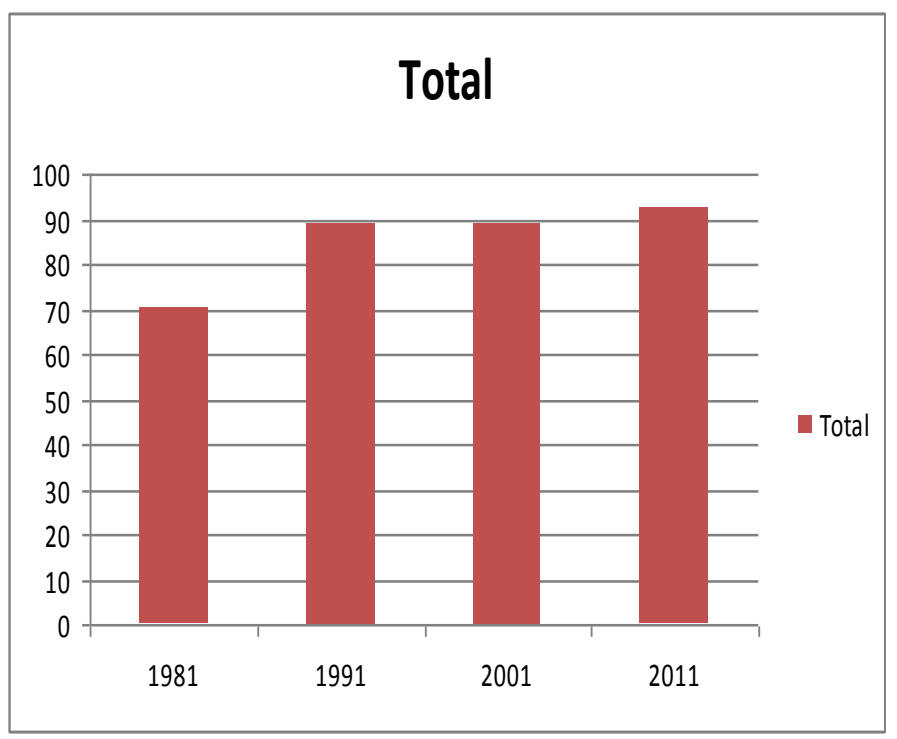


Fig. 9

The Illiteracy - Literacy Ratio (ILR) is computed for the district which shows the proportion of illiterates (I)/ 100 literates (L) in the population. Lesser the value more will be the concentration of literates and if it crosses 100, the concentration of illiterates will be more. ILR of the district for the past four censuses showed a positive concentration of literates' population. This decreased from 43.71 in the year 1981 to 18.52 in the year 2011(Table 3).

Table 3

\begin{tabular}{|c|c|}
\hline Year & Illiteracy - Literacy Ratio (ILR) \\
\hline 1981 & 43.71 \\
\hline 1991 & 28.51 \\
\hline 2001 & 26.41 \\
\hline 2011 & 18.52 \\
\hline
\end{tabular}

Among the panchayats, Ulloor panchayat $(30,468)$ had the highest concentration of literates in the year 1981 with 168,282 males and 14,186 females, followed by Parassala and Sreekaryam panchayats. Poovachal panchayat $(22,537)$ had the highest concentration of illiterates. The 2011 census revealed that Sreekaryam panchayat $(45,364)$ had the highest literacy followed by Karakulam $(45,001)$. Illiterate people concentration is highest in Kadinamkulam $(10,738)$ panchayat.

\subsection{Occupation Structure}

The study of the total number of workers during 1981 census was 784,274 of which 703,340 are main workers and 80,934 are marginal workers. Main working population is highest in Thiruvananthapuram Corporation $(127,346)$ followed by Nedumangad Municipality $(11,793)$. Among the panchayats, Parassala accounted for 10,719 workers, followed by Ulloor and Thiruvallam with 10,514 and 10,452 each. Ottoor $(2,757)$ and Pallickal $(2,792)$ are the panchayats with lowest number of working population. Workers engaged in service sector were 379,432. Agricultural labourers accounted for 234,668, cultivators were 61,141 and those engaged in household industries were 28,099. Among the total population, 1,811,383 are non workers of which 685,751 are male and 116,087 are female.

2011 census saw an increase in the total number of workers to 1,231,669 with 864,101 male workers and 367,568 female workers. Main workers constituted 921,282 and marginal workers 310,387. Highest working population is still in the Thiruvananthapuram Corporation $(298,817)$. 19,658 workers are there in Neyyatinkara municipality. Karakulam panchayat has 15,194 workers followed by Kadinamkulam panchayat with 13,808 workers. Workers engaged in service sector increased to 819,263 and all other sectors showed a decreasing trend. Agricultural labourers decreased to 55,785, Cultivators to 26,756 and Household workers decreased to 19,478 . Non workers accounted for $2,069,758$ of which 717,577 are male and 1,352,181 are female.

Table 4

Growth Rate of Main Workers (1981-2011)

$\begin{array}{llll}\text { Workers } & \text { Male } & \text { Female } & \text { Total } \\ \text { Cultivators } & -2 & -0.108 & -1.87 \\ \text { Agricultural Labourers } & -2.51 & -2.63 & -2.54 \\ \text { Household, Manufacturing, Servicing and Repair } & -0.42 & -1.71 & -1.02 \\ \text { Other Services } & 3.75 & 4.21 & 3.83 \\ \text { Total } & 0.88 & 1.546 & 1.03\end{array}$

The growth rate of main worker is 1.03 for the three decades and it is 0.88 for males and 1.546 for females. Among the category of workers, other workers are seen having the highest growth rates (Table 4).

\section{Conclusion}

The present study tries to analyse the development of the district on the basis of demographic variables. The changes in the growth rate of the population are slow and the variations in growth between decades are also decreasing which is an achievement. The district also has a favourable sex ratio like the other districts in Kerala. The study shows that the district needs a good foresight in planning as it has high population density with youth population constituting a good portion of the occupants. The district also shows an increase in the urban population and this change of people from rural to urban can result in greater production of goods and services, but it can also create congestion, pollution, and a greater demand for housing, clean water, sanitation facilities, recreation areas, public transport, health care and education. If the government could not provide the necessary services for quality living, the result may be a lower standard of living for everyone. Occupation structure also 
stresses the fact that more people are interested in tertiary activities and so more job opportunities should be introduced in this sector without harming other sectors. A more elaborate study can be made possible with the inclusion of migration details and marital status data of the district.

Thus the population study is an essential component of many activities, social and market research, physical and environmental planning, administration, and in particular people-centred development planning. The magnitude of the threat to the ecosystem is linked to human population size and resource use per person. Resource use, waste production and environmental degradation are accelerated by population growth. As human numbers further increase, the potential for irreversible changes of far reaching magnitude also increases. Political will and intelligent use of science and technology and human ingenuity can remove many constraints on improving human welfare, finding substitutes for wasteful practices, and protecting the natural environment. Plans for the well-being in the future would therefore be more efficient if changes in the population in these respects would be foreseen (Peter R Cox, 1957).

\section{Acknowledgements}

The author wish to thank DST for the financial support that made this study possible.

\section{References}

[1] Blau, P.M., (1974), Presidential Addresss: Parameters of Social Structure, American Sociological Review 39 (5): 615 -635

[2] Bouge, D.J., (1969), Pricinples of demography, New York, John Wiley.

[3] Cox, Peter R. (1957), Demography, Syndics of the Cambridge University Press.

[4] Dudley L Poston and Michael Micklin (etd.), Handbook of Population, Springer, New York.

[5] Horiuchi,S., and Preston, S.H., (1988), Age Specific Growth Rates: The legacy of Past Population Dynamics. Demography, 25:429-441.

[6] Jain, A.K, and Visaria, P.P., (1988), Infant Mortality in India: Differentials and Determinants, Sage Publications, New Delhi.

[7] Keyfitz, N. (1965), Age distribution as a challenge to development. American Journal of Sociology 70:659-668

[8] Keyfitz, N., and Flieger, W., (1971), Population: Facts and methods of demography. San Francisco: W.H. Freeman.

[9] Mitra, K.C,(2012) Population Geography, Wisdom Press, New Delhi.

[10] Nair, N.S., P.R. Kutty, D. Archana, S. Chandrasekhar and R.S.P. Rao, (1995), Female literacy as a determinant of sociodemographic status and Infant Survival, Health and Population -Perspectives and Issues, 18 (4): 190-202.

[11] Prabhakar, V.K., (2001) Population and Environment, Anmol Publications Private Ltd., New Delhi.

[12] Srinivasan, K., Basic demographic techniques and applications, Sage Publications, New Delhi.

[13] Turner, J.H. (1975), Marx and Simmel Revisited : Reassessing the foundation of Conflict Theory. Social Forces 53 (4): 618 -627.

[14] United Nations, (1970), Principles and Recommendations for the 1970 Censuses, UN, New York.

[15] Registrar General India (1981), Census of India, 1981 Series I, India, Part II B (1) General Economic Tables, Government of India, New Delhi.

[16] United Nations (1963), Methods of Analyzing Census Data on Economic Activities of the Population, Department of Economic and Social Affairs, Population Studies, No. 43, United Nations, New York. 